Insight, part of a Special Feature on The Privilege to Fish

\title{
Haida Marine Planning: First Nations as a Partner in Marine Conservation
}

\author{
$\underline{\text { Russ Jones }}^{1}$, Catherine Rigg ${ }^{1}$, and Lynn Lee ${ }^{2}$
}

\begin{abstract}
The Haida Nation is involved in an integrated marine planning initiative in northern British Columbia, Canada. The Haida continue to occupy traditional territory in and around Haida Gwaii, or the Queen Charlotte Islands, and are engaged in a larger planning process for the Pacific North Coast Integrated Management Area (PNCIMA). This initiative is in the early planning stage, focused on capacity building and creating enabling conditions for co-governance. Court decisions, government policies, and a modern treaty process are driving short- and long-term efforts to resolve issues of Aboriginal ownership and resource access, both on land and in the ocean. As a result, the PNCIMA process is being led by two levels of government, First Nations and federal, reflecting changing perceptions of Aboriginal title and rights in British Columbia. The Haida have been resource owners and managers on Haida Gwaii for millennia, and continue to apply traditional knowledge and experience to marine-use planning and fisheries management. The Haida approach is place based and guided by fundamental Haida ethics and values such as respect, balance, and reciprocity. We describe these values and discuss the emerging role of First Nations in integrated oceans management in the context of the six themes: lessons from land-use planning; the PNCIMA governance structure; the relationship of values to planning outcomes; developing an ecosystembased management framework; applications of traditional knowledge, based on a study of Haida marine traditional knowledge currently in progress; and linking marine planning at various scales. On Haida Gwaii, collaborative marine planning is expected to result in improved protection of Haida Gwaii waters for future generations, greater Haida participation in management decisions, and increasing emphasis on sustainability of both local fisheries and communities.
\end{abstract}

Key Words: Aboriginal rights; fisheries management; indigenous peoples; integrated coastalmanagement; marine planning; oceans governance

\section{INTRODUCTION}

In partnership with neighboring First Nations and the Canadian federal government, the Haida are engaging in a process to develop integrated management plans for the Pacific North Coast Integrated Management Area (PNCIMA) in the northwest coast of British Columbia (BC). On Haida Gwaii, or the Queen Charlotte Islands, the initiative is being led by the Council of the Haida Nation $(\mathrm{CHN})$, the governing body for the Haida Nation under the Haida Constitution (http://www.haidanat ion.ca/), and is an example of local communitybased management and co-governance during the planning phase for integrated oceans management in Canada. The CHN works closely with Old
Massett Village Council and Skidegate Band Council, located in Old Massett and Skidegate, respectively (Fig. 1). Other First Nations engaged in marine planning include Heiltsuk, Kitasoo/ Xaixais, Nuxalk, and Wuikinuxv on the BC Central Coast, and Gitga'at, Gitxaala, Haisla, Metlakatla, Kitsumkalum, and Kitselas on the North Coast. We explore how First Nations values and interests, expressed as part of the integrated management process in PNCIMA, are likely to result in outcomes that support conservation and sustainable use.

The PNCIMA is a "large ocean management area" (LOMA) on the $\mathrm{BC}$ coast that stretches from northern Vancouver Island to the Alaskan border in the United States (Fig. 2). Prince Rupert is the 
Fig. 1. British Columbia First Nation communities, including the Haida, involved in marine-use planning on Canada's Pacific north coast

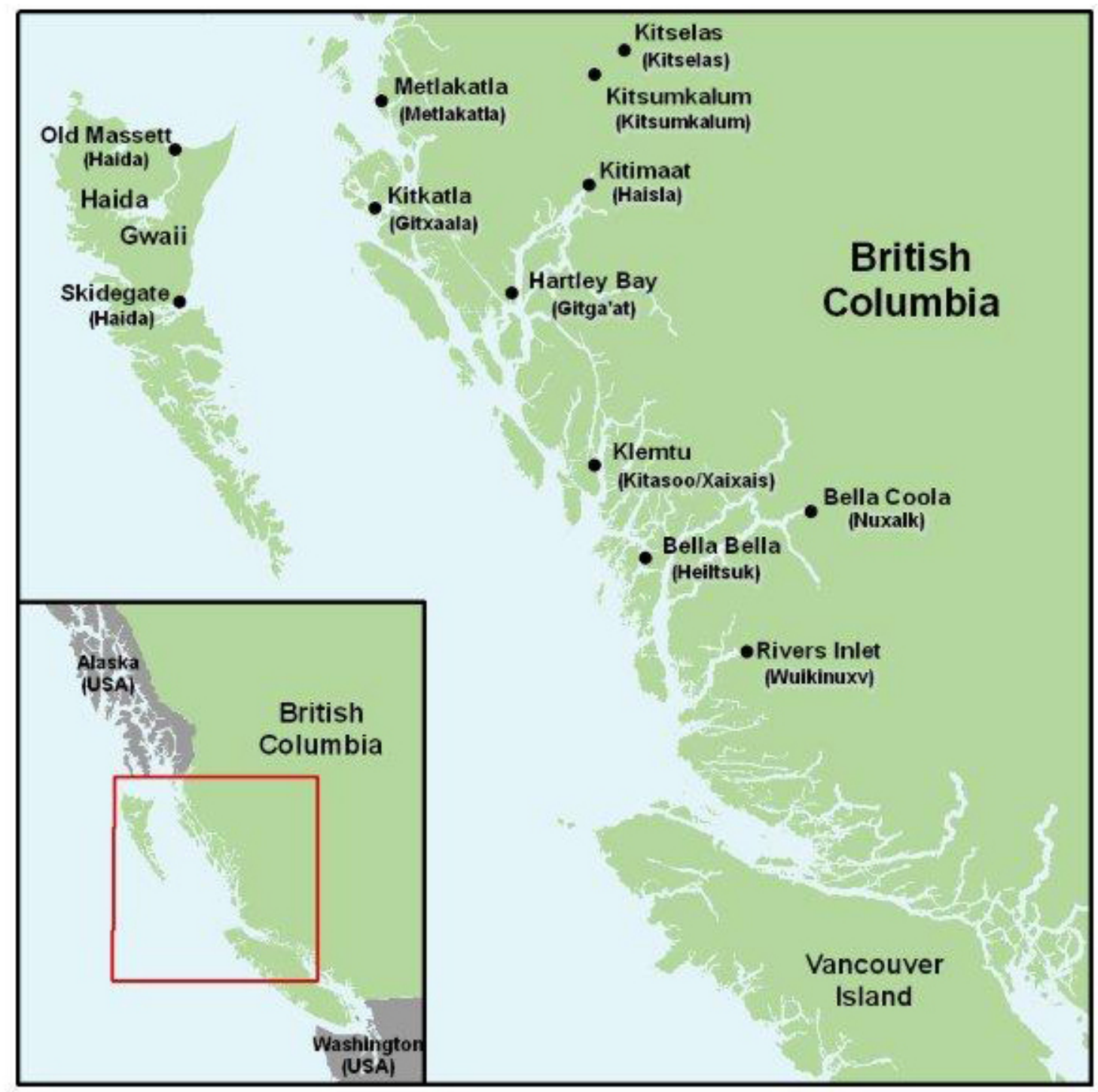

largest city in the area with a population of approximately 13000 . Other communities are indicated on the map for reference. In 2005, PNCIMA was identified as one of five national pilot areas for integrated management (Fisheries and Oceans Canada 2005). Approximately 75000 people live within the boundaries of the PNCIMA (J. Booth, N. Dale, and D. Haggerty, unpublished manuscript), about a third of whom are of First
Nations ancestry. Despite the region's low population density, the adjacent marine ecosystems are subject to a variety of existing and potential ecological threats. These include: offshore oil and gas, commercial finfish aquaculture, marine transportation, climate change, introduced species, and bottom trawling (PNCIMA Secretariat 2009; J. Booth, N. Dale and D. Haggerty, unpublished manuscript). With federal government support, 
Fig. 2. Location of Pacific North Coast Integrated Management Area

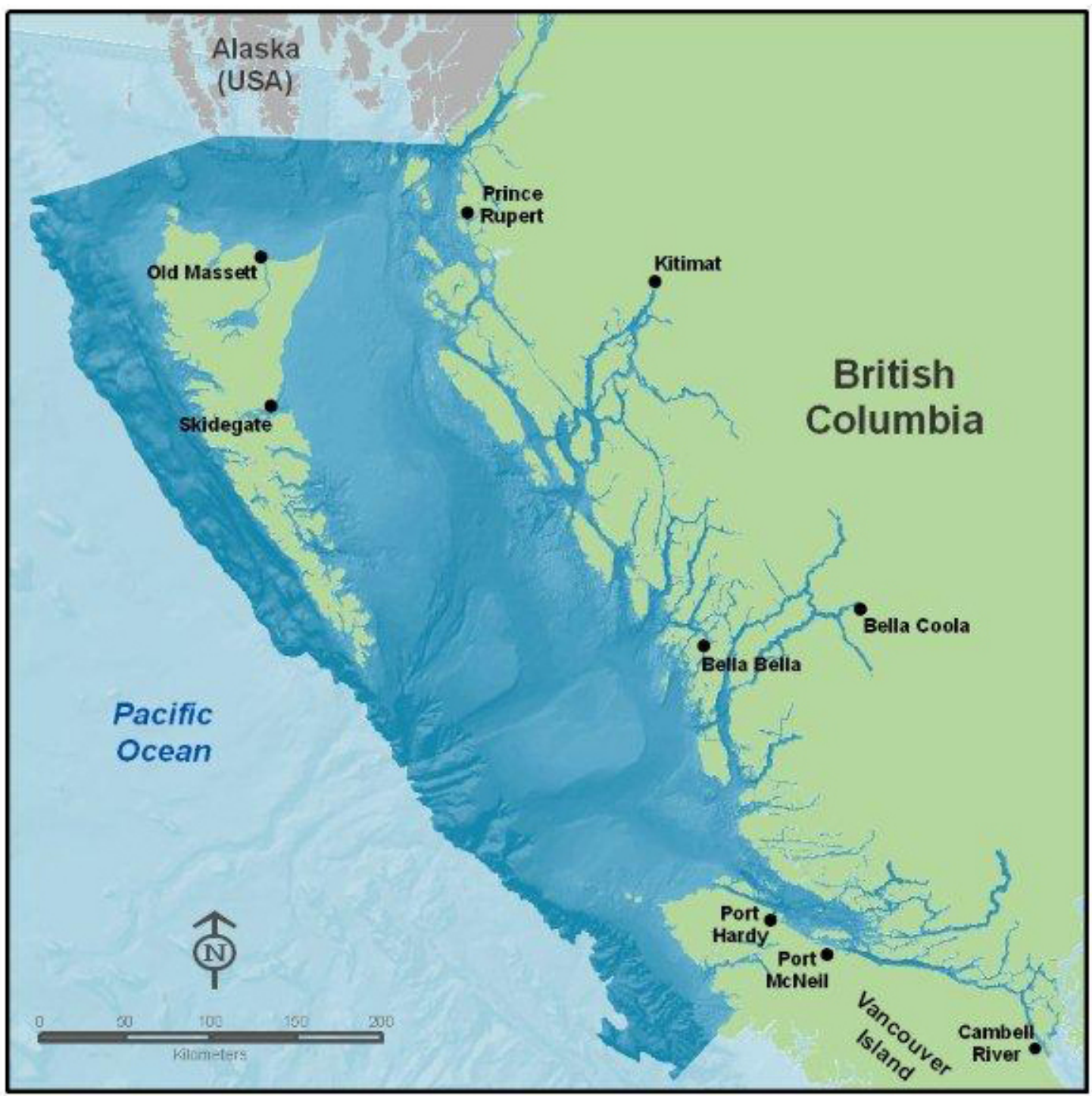

First Nations have organized themselves to facilitate engagement in marine planning on a range of scales, from local to LOMA, to address these ecological issues and accompanying challenges.

Integrated coastal management is defined as a continuous and dynamic process by which decisions are made for the sustainable use, development, and protection of coastal and marine areas and resources (Cicin-Sain and Knecht 1998). Fisheries and
Oceans Canada (DFO) is the lead agency for integrated oceans management in Canada and their approach provides opportunities for collaborative management of ocean areas with Aboriginal peoples (Government of Canada Oceans Act 1997, Fisheries and Oceans Canada 2002). Until recently, government policies in Canada and BC have tended to displace First Nations from land and marine resources, including fisheries (Coates 1999, Harris 2001, 2002). 
Treaties were never signed in most of BC, but court decisions have encouraged governments to negotiate and resolve resource-use issues with First Nations, for example, R. v. Sparrow 1990 S.C.R. 1075, Delgamuukw v. British Columbia 19973 S. C.R. 1010, Haida Nation v. British Columbia (Minister of Forests) 20043 S.C.R. 5112004 SCC 73. These decisions led to a modern treaty process to resolve ownership and jurisdictional issues but progress in negotiations has been slow. As a result, a variety of interim agreements with First Nations have been negotiated in advance of signed treaties.

Court decisions in Canada have changed perceptions of Aboriginal title and rights and have also affected government policies and approaches to resource development (Jones 2006). In Delgamuukw v. BC, the courts laid out a test for Aboriginal title as existing if a First Nation occupied the land in 1846. Following the Delgamuukw decision, Haida Nation v. BC was launched in response to the provincial government ignoring Haida title to forest lands. Even though Haida title has yet to be proven in court, the trial judge stated that the Haida have a strong prima facie case for title. The resulting Supreme Court decision in favor of the Haida requires the government to now consult with First Nations and provide accommodation if actions of the Crown might adversely affect Aboriginal rights and title. Accommodation can require full consent by First Nations before actions of the Crown may proceed. Aboriginal title and rights to the sea and its fisheries resources have been the subject of recent litigation by Nuu-chah-nulth First Nations (Ahousaht Indian Band and Nation v. Canada [Attorney General] 1990 BCSC 1494).

Integrated oceans management provides opportunities to explore co-governance arrangements and develop partnerships while promoting conservation and sustainable use of marine resources. Using the Haida example, First Nations' approaches to ocean management are based on values and place-based traditional knowledge. Building on the principles and values outlined in two introductory documents Towards a Marine Use Plan (Council of the Haida Nation 2007) and Into the Deep Blue: Marine Ecosystem-based Management (Coastal First Nations-Turning Point Initiative 2009), it is argued that the cultural approach adopted by the Haida is likely to promote marine planning outcomes that balance conservation with sustainable use of marine resources over the long term, benefiting the Haida and all Canadian citizens.

\section{HAIDA APPROACH TO MARINE PLANNING}

In 2007, the CHN completed an internal strategic planning process in preparation for collaborative marine planning. At the same time, DFO prepared for integrated management planning by compiling background information to support a public planning process. In December 2008, DFO also entered into a memorandum of understanding on collaborative oceans governance with First Nations of the BC North Coast, Central Coast, and Haida Gwaii as represented by Coastal First NationsTurning Point Initiative and North Coast Skeena First Nations Stewardship Society (Fisheries and Oceans Canada and First Nations of the Pacific North Coast 2008). This bilateral governance arrangement, is an expression of DFO's mandate to engage in regional planning, and First Nations' interest in local community-based management and multiscale planning.

Specifically, the Haida approach to marine planning is described in a public document Towards a Marine Use Plan for Haida Gwaii (Council of the Haida Nation 2007). It presents the following Haida marine vision:

Haida culture is intertwined with all of creation in the land, sea, air and spirit worlds. Life in the sea around us is the essence of our well-being, and so our communities and culture.

Yet here, as around the world, an insatiable human appetite is depleting the oceans. Some species are diminished or gone, and many habitats are impoverished.

We know that our culture depends on the sea around us, and that the well-being of every community and Nation is at risk. It is imperative that we bring industrial marine resource use into balance with, and respect for, the well-being of life in the sea around us.

We must take steps today to achieve a future with healthy intact ecosystems that 
continue to sustain Haida culture, communities, and an abundant diversity of life, for generations to come.

The six Haida ethics and values upon which this marine vision is built (Council of the Haida Nation 2007) are listed below in Haida, then English:

\section{Yahguudang or Yakguudang. Respect.} Respect, for each other and all living things, is rooted in our culture. We take only what we need, we give thanks, and we acknowledge those who behave accordingly.

\section{Giid tll'juus. "The world is as sharp as the} edge of a knife."

Balance is needed in our interactions with the natural world. If we aren't careful in everything we do, we can easily reach a point of no return. Our practices and those of others must be sustainable.

3. Gina waadluxan gud ad kwaagiida. "Everything depends on everything else." This principle is comparable to an integrated approach to management.

\section{Isda ad diigii isda. Giving and Receiving.} Giving and receiving (reciprocity) is a respected practice in our culture, essential in our interactions with each other and the natural world. We continually give thanks to the natural world for the gifts that we receive.

\section{Gina k'aadang.nga gii uu tl'k'anguudang. Seeking Wise Counsel.}

Our elders teach us about traditional ways and how to work in harmony. Like the forest, the roots of our people are intertwined. Together we consider new ideas and information in keeping with our culture, values, and laws.

\section{6. 'Laa guu ga kanhllns. Responsibility.}

We accept the responsibility passed on (to us) by our ancestors to manage and care for the sea and land. We will ensure that our heritage is passed on to future generations.

These six ethical principles and values are also embodied in a working definition of Haida ecosystem-based management (EBM) for marineuse planning:
Respect is the foundation of ecosystembased management. It acknowledges that the land, sea, air and all living things, including the human community, are interconnected and that we have the responsibility to sustain and restore balance and harmony. (Coastal First Nations - Turning Point Initiative 2009)

Haida values are a distinct expression of Haida culture. They share some commonalities with natural and social science descriptions of EBM (Table 1). Here, we highlight potential applications of Haida values to the EBM approach and compare these values to common principles in resource use (e.g., Convention on Biological Diversity 2000, Pope and Symes 2002, Food and Agricultural Organization 2003, McLeod et al. 2005, Arkema et al. 2006).

The Haida application of cultural values in resource management has precedent in both local fisheries management and the recently completed land-use planning process on Haida Gwaii. Yahguudang, respect, was the foundation for the Haida Land Use Vision (Council of the Haida Nation 2005) that ultimately led to a Haida Gwaii land-use agreement (Council of the Haida Nation and Province of British Columbia 2007). The agreement established locally sustainable forestry practices, reducing the annual cut from 2.2 million to approximately 800000 meters $^{3}$ per annum, and created a network of terrestrial protected areas, which resulted in $52 \%$ of the land area and $72 \%$ of the Haida Gwaii coastline receiving protected area designation. Application of Haida values to in-river sockeye, herring spawn-onkelp, and ocean sport fisheries management are also discussed by Jones and Williams-Davidson (2000) and Jones (2007). The Haida values of respect and balance also have similarities to the modern concepts of the precautionary approach and sustainability. For example, the Haida manage a river sockeye fishery that blends fisheries science and Haida traditional knowledge by basing management decisions on modern stock assessment data and Haida knowledge of the sockeye run, both of which are discussed in-season at Haida community meetings. The Haida have also demonstrated against perceived over-harvesting of local herring stocks and object to the practice of catch-and-release in the recreational fishery, based on the Haida belief that playing with your food is disrespectful of living creatures that give their lives as gifts to humans for sustenance. 
Table 1. Comparison of Haida and scientific principles for ecosystem-based management

\begin{tabular}{|c|c|c|}
\hline Haida Principle & Parallel Scientific Principle & Possible Applications \\
\hline Respect & $\begin{array}{l}\text { Precautionary } \\
\text { approach }\end{array}$ & $\begin{array}{l}\text { Account for well-being of all species. } \\
\text { Prevent wasteful fisheries practices (e.g., } \\
\text { bycatch). }\end{array}$ \\
\hline Balance & $\begin{array}{l}\text { Sustainable use over } \\
\text { the long term }\end{array}$ & $\begin{array}{l}\text { Ensure sustainable fisheries. } \\
\text { Consider ecological and socioeconomic } \\
\text { information. }\end{array}$ \\
\hline $\begin{array}{l}\text { Interconnectedness } \\
\text { (everything depends } \\
\text { on everything else) }\end{array}$ & $\begin{array}{l}\text { Integrated } \\
\text { management }\end{array}$ & $\begin{array}{l}\text { Link to land-use planning decisions. } \\
\text { Consider compatibility of marine activities and } \\
\text { cumulative impacts of developments. }\end{array}$ \\
\hline $\begin{array}{l}\text { Giving and receiving } \\
\text { (reciprocity) }\end{array}$ & Equitable sharing & $\begin{array}{l}\text { Appreciate the inherent value of all living things } \\
\text { in planning. } \\
\text { Develop fair and equitable approaches to sharing } \\
\text { limited resources. }\end{array}$ \\
\hline Seeking wise counsel & $\begin{array}{l}\text { Adaptive management } \\
\text { Best information }\end{array}$ & $\begin{array}{l}\text { Use traditional knowledge. } \\
\text { Improve understanding through research, } \\
\text { education, and monitoring. }\end{array}$ \\
\hline Responsibility & Inclusive and participatory & $\begin{array}{l}\text { Respect for Haida title and rights. } \\
\text { Ensure sufficient enforcement capacity. }\end{array}$ \\
\hline
\end{tabular}

The Haida approach to resource management is based on the understanding that humans are part of the ecosystem. As a result, the inclusion of socioeconomic values and equitable approaches to sharing are necessary considerations in Haida decision making. For example, benefits to community and the distribution of wealth within communities factor into decisions regarding access to local fisheries. Wealth is to be shared, and an expression of reciprocity in Haida society is the continuing practice of the potlatch. At a potlatch, the giving of gifts provides status and honor to the giver while requiring obligations for the recipient, effectively resulting in the equitable redistribution of limited resources. Finally, the Haida value of "seeking wise counsel" is an expression of Haida respect for elders and appreciation for their life experience and the knowledge passed on by ancestors. The value of this type of experiential knowledge is increasingly acknowledged in Canadian legislation, for example, the Oceans Act, particularly as it relates to informing local-level resource management and planning. In this way, the contributions of First Nations traditional knowledge are recognized as a necessary complement to contemporary scientific understanding of ecosystem dynamics.

An ecosystem overview assessment recently completed by DFO lacked information on First Nation traditional use and knowledge (see Lucas et al. 2007). In an effort to address this data gap, a collaborative effort by First Nations is currently underway to document traditional use and knowledge for the PNCIMA by means of recorded interviews. In the Haida communities of Skidegate and Massett, both short semi-structured interviews and longer oral history interviews are being conducted with Haida individuals who have extensive experience in local marine resource use and the marine environment of Haida Gwaii. Participants were selected in consultation with the CHN with priority placed on interviewing elders and people with fishing experience. All interviews were audio- or video-recorded and fully transcribed, and spatial information is being documented on 
Fig. 3. Governance model for Pacific North Coast Integrated Management Area (PNCIMA) planning

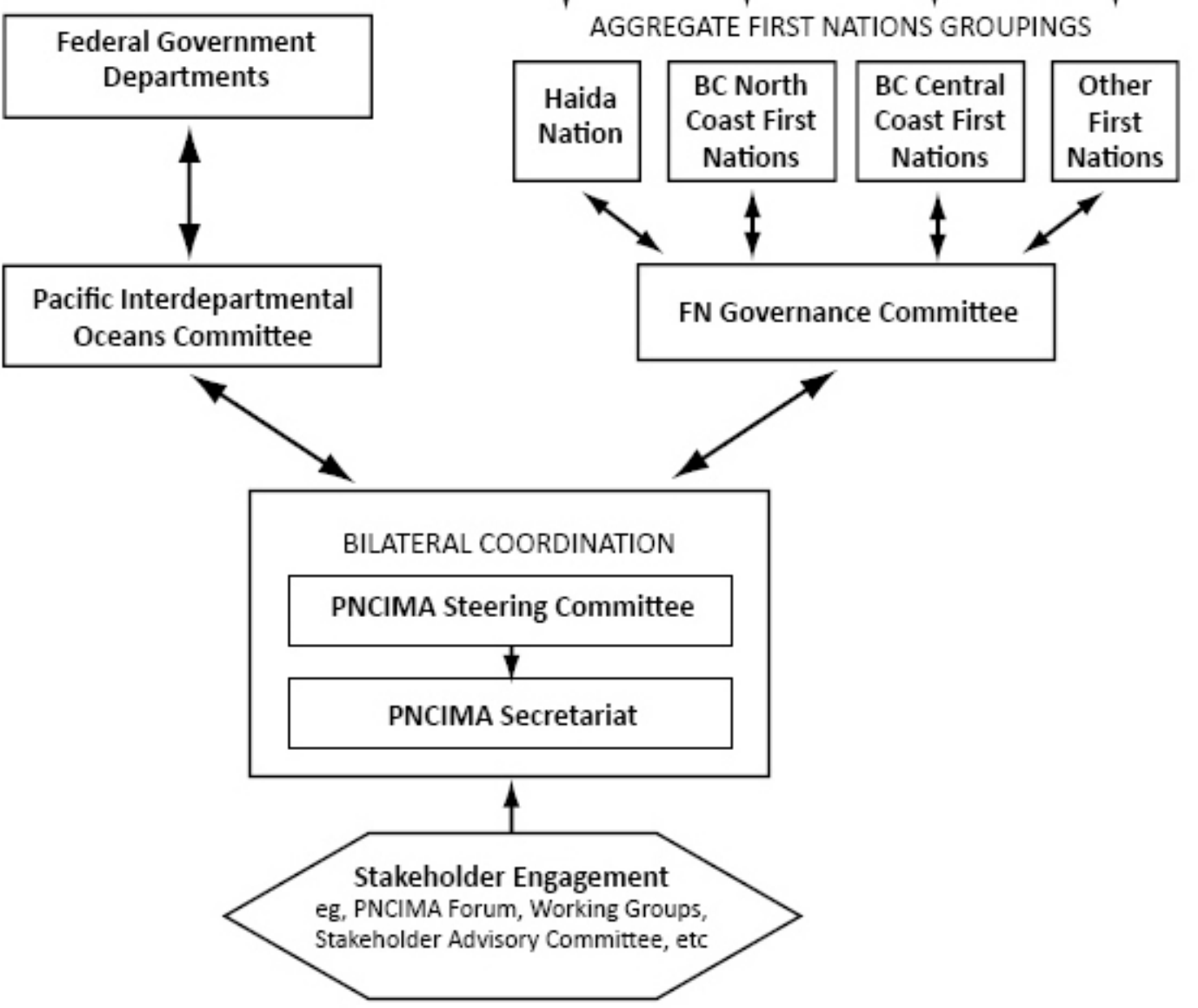

marine charts, digitized, and entered into a database. First Nations engaged in marine-use planning in the PNCIMA, including the Haida Nation, are using a consistent approach to record information about specific marine traditional knowledge themes, following common formats for spatial mapping and associated databases for map features. Despite variations in project methodology between First Nations, relatively consistent products are anticipated across traditional territories because of First Nations' coordination within the PNCIMA planning process. Documentation of marine traditional knowledge is still at a preliminary stage, but once products are available, results can then be
INDIVIDUAL FIRST NATIONS

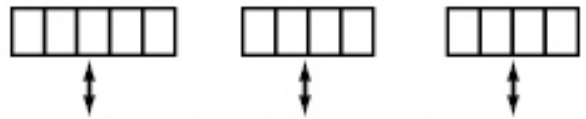

AGGREGATE FIRST NATIONS GROUPINGS 
Fig. 4. Marine-use planning process from the Haida perspective. First Nations is abbreviated here as FN, Fisheries and Oceans Canada as DFO.

Haida Nation Process

\section{First Nations \\ Process}

DFO - FN

Process

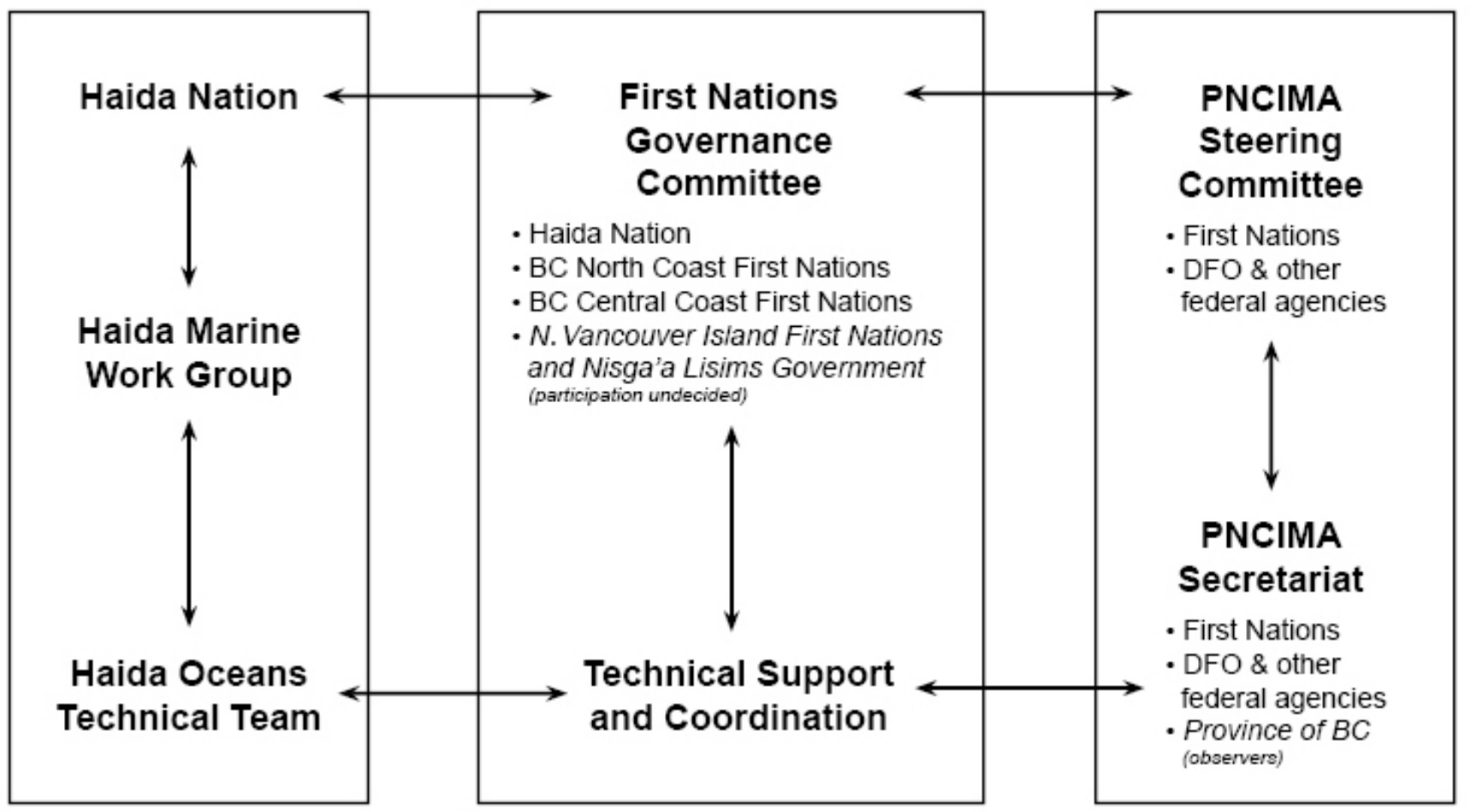

First Nations-Turning Point Initiative 2007, Alley and Topelko 2007). Because no treaties or land claims agreements are in place to clarify relationships and address ownership and management of land and ocean spaces in the region, these relationships are based on respect for independent government authorities, both within First Nations and with the federal government. Different perspectives on ownership are put aside in the interest of working toward collectively shared goals and objectives.

From a Haida perspective, the governance structure for integrated marine-use planning in the PNCIMA has three tiers (Fig. 4). The first is an internal process within the Haida Nation and is being led by the CHN. A Haida Marine Work Group, appointed by the CHN, has met monthly since August 2006 and is supported by a three-person technical team. It involves representatives from $\mathrm{CHN}$, Old Massett Village Council, Skidegate Band Council, a Council of Hereditary Chiefs, and the Haida public.

The second is a process among First Nations and includes a First Nations Governance Committee and Area Technical Teams that represent three areas within the PNCIMA (Haida Gwaii, BC North Coast First Nations, and BC Central Coast First Nations). These bodies provide a forum for First Nations to have policy and technical dialogue. Some First Nations have not yet decided whether to participate in PNCIMA planning, including the Northern Vancouver Island First Nations and the Nisga'a Lisims Government.

The third tier is between First Nations and DFO. First Nations and Canada have begun to engage through a high-level PNCIMA Steering Committee, 
the PNCIMA Secretariat, and bilateral working groups to address operational issues (Fig. 3). To date, the Steering Committee and Secretariat have focused on the public launch of PNCIMA and the development and review of background material to support the planning process.

The memorandum of understanding on collaborative oceans governance establishes a governance framework for the marine-use planning process in the PNCIMA that is based on equal and respectful engagement of both federal and First Nations governments. The BC provincial government has also pledged support for the process but has not formally engaged at a government-to-government level because of limited resources and capacity ( $\mathrm{J}$. Alley, personal communication).

In March 2009, the PNCIMA initiative was publicly launched, and over 300 representatives of government, industry, environmental organizations, and other stakeholders convened at a two-day forum to discuss visions for the process and mechanisms for broader stakeholder engagement. The inclusion of stakeholders will add another tier to the planning process as it is currently conceptualized, and is recognized by both governments as a critical component of successful regional and local-scale planning. As a result, the PNCIMA Steering Committee is committed to the development of a formal stakeholder engagement strategy, with a terms of reference for the process, organization of community meetings within the region, and the formation of issue-specific working groups to address key marine-use activities in the PNCIMA. Importantly, these commitments, along with recognition that the PNCIMA initiative must be integrated with other ocean planning processes in the region, such as designation of the Gwaii Haanas National Marine Conservation Area Reserve and proposed new protected areas, were presented as collaborative priorities by both First Nations and federal government representatives at the public forum.

\section{DISCUSSION}

Integrated management in Canada is gradually progressing, and pilot projects such as PNCIMA provide an opportunity for adaptive learning. Integrated management initiatives evolve through a policy cycle (Olson et al. 1997). The PNCIMA is still at an early stage in this policy cycle when outcomes are less tangible and the process is best described as creating "enabling conditions" (Olson 2003). Creation of a unified First Nations voice in the region and organization of First Nations into three planning areas within the PNCIMA, i.e., Haida Gwaii, North Coast, and Central Coast, provides an opportunity to make interim progress on integrated management, even where there are outstanding questions of resource ownership. It also enables First Nations to effectively function at a government-to-government level, thereby providing opportunities for changes to the status quo, such that planning outcomes are consistent with First Nations values and approaches to marine resource management. First Nations participation in integrated marine-use planning is therefore anticipated to result in the creation of a marine protected area network and greater emphasis on sustainable fisheries practices.

The emerging role of First Nations in integrated oceans management relates to several key aspects of effective oceans planning, each discussed next in detail: lessons from land-use planning; PNCIMA governance structure; relationship of values to planning outcomes; developing an EBM framework; applications of traditional knowledge; and, linking marine planning at various scales.

\section{Lessons from land-use planning}

First Nations have been a catalyst for change in BC resource management policy and law. Recent landuse agreements with First Nations are establishing a significant portion of the land base as new protected areas. These designations align with government and international policies supporting networks of protected areas on land and in the ocean. On Haida Gwaii, the land-use planning process was co-managed by the Council of the Haida Nation and the Province of BC, and the final Haida Gwaii Strategic Land Use Agreement resulted in a significant increase in protected areas (Council of the Haida Nation and Province of British Columbia 2007). Also, in accordance with the agreement, the Province of $\mathrm{BC}$ and the $\mathrm{CHN}$ are currently in the process of developing boundaries and management plans for nearshore and foreshore areas adjacent to terrestrial protected areas on Haida Gwaii. These areas will be de facto marine protected areas in that they will affect coastal zone usages that fall within provincial jurisdiction such as aquaculture tenures, log dumping, and kelp harvesting. They will still 
have to be recognized federally to address aspects of federal jurisdiction, for example, fisheries and marine transportation activities.

Land-use decisions for the new Great Bear Rainforest on the Central and North Coasts similarly afforded protection for more than $30 \%$ of the land base (Province of British Columbia 2006). Landuse planning processes in these three areas were led by the Province of BC and First Nations, and each process involved multistakeholder planning tables. In 2005, the Province's approach to resource management and planning was codified in a "new relationship" agreement that commits to a government-to-government relationship with First Nations, shared decision making about the uses of land and resources, and revenue sharing to reflect Aboriginal rights and title interests (Province of British Columbia 2005). Involvement of First Nations in integrated oceans management planning is likely to result in comparable conservation designations and improved collaborative opportunities for First Nations' involvement in the management of marine resources within traditional territories.

\section{PNCIMA governance structure}

The memorandum of understanding (MOU) signed in December 2008 establishes a governance structure for the PNCIMA initiative in which engagement of First Nations occurs at a government-to-government level. The MOU also recognizes that the Province of $\mathrm{BC}$ may choose to participate in the future and also outlines a proposed approach to broadly engage stakeholders in the region.

Although the Province of BC is not directly involved in PNCIMA, it engages with the federal government on a number of related levels. In 2004, the relationship between Canada and BC was formalized through a Memorandum of Understanding Respecting the Implementation of Canada's Oceans Strategy on the Pacific Coast of Canada, although subsidiary agreements foreseen under the memorandum of understanding have not yet been ratified (Fisheries and Oceans Canada and BC Ministry of Agriculture, Food and Fisheries 2004). However, work related to these subsidiary agreements and other collaborative oceans projects has occurred through federal and provincial participation on a Canada-BC Oceans Coordinating Committee and Federal-Provincial Oceans Regional Implementation Committee. Despite the lack of formal provincial engagement in the PNCIMA process, $\mathrm{BC}$ has pledged to make all provincial resource information and data freely available to the planning teams, to provide any required clarifications of provincial policy, and to offer other marine planning expertise as available.

In the context of governance, it is useful to compare the PNCIMA process to other ongoing federal integrated management planning efforts. The PNCIMA process is similar to the Beaufort Sea Integrated Management Planning Initiative (BSIMPI), wherein the governance structure is consistent with a modern land claim agreement [ERRATUM]. The 1984 Inuvialuit Final Agreement established comanagement boards for game, fisheries, and wildlife that involve joint decision making by the Inuvialuit, Canadian federal government, and the territorial government. Integrated oceans management was not addressed in the agreement but, based on functioning Inuvialuit co-management structures, a senior management committee and working groups have been established as part of BSIMPI. Although these are not formal co-management bodies, their structure is consistent with the principles outlined in the Inuvialuit Final Agreement (Fast et al. 2005).

Northern Arctic communities have been characterized as having less complex coastal management issues than most parts of the world and a well established governance framework through Aboriginal land claims agreements (Berkes et al. 2007). These communities are also facing relatively rapid social and environmental change, and through integrated oceans management, Inuit Qaujimajatuqangit, or traditional knowledge, provides insights and contributes to planning outcomes such as marine mammal management and monitoring of climate change effects. For example, issues addressed through the BSIMPI planning process include the designation of marine protected areas for beluga whales and the management of oil and gas development (Berkes et al. 2007). Although the PNCIMA initiative is relatively new and outcomes are uncertain, the designation of marine protected areas is recognized as one mechanism to achieve conservation results in planning. First Nations involvement in the selection, design, and implementation of proposed areas is also more likely to make management of these areas 
successful over the long term (Jones and Guénette 2002). Thus, First Nations in PNCIMA have the potential to make similar contributions as the BSIMPI process by addressing key marine resource issues in the Pacific region, and using planning tools such as the designation of protected areas.

In contrast to the Beaufort Sea example, there has been limited First Nations involvement in the Eastern Scotian Shelf Integrated Management (ESSIM) Area planning process (Rutherford et al. 2005) [ERRATUM]. This is possibly because of existing historic treaties with First Nations on the east coast, and therefore limited government interest in collaborative activities because of less uncertainty in First Nations land and resource ownership, as well as ESSIM's offshore location. Unlike ESSIM, PNCIMA planning will address both coastal and offshore marine-use activities. On the west coast of Canada, the political uncertainty about the implications of Aboriginal title and the requirement that federal and provincial governments consult with and accommodate affected First Nations has motivated a more proactive approach to cooperative governance and joint decision making. Although an ESSIM management plan has been prepared (Fisheries and Oceans Canada 2007), it does not provide details of specific actions, and a recent review of lessons learned from ESSIM and other collaborative ocean initiatives in Atlantic Canada indicated that the transition from planning principles to actions has not systematically occurred (Bastien-Daigle et al. 2008). This may be because of their early stage in the policy cycle, which typically lasts 8 to 15 years for coastal management programs (Olson et al. 1997), or a lack of critical common issues or catalysts for change in oceans governance or management.

All three pilot projects, i.e., PNCIMA, BSIMPI, and ESSIM, have different governance frameworks and are at early stages, with planning outcomes yet to be realized. Significantly, the governance framework for PNCIMA engages First Nations at a government-to-government level in advance of resolved treaty agreements. First Nation participation as leaders in the PNCIMA process, operating collaboratively with DFO, will enable the integration of cultural values into marine-use planning where they might otherwise be absent. On Haida Gwaii, these values are clearly rooted in a conservation ethic that seeks to ensure sustainable, precautionary, and ecosystem-based management of marine resources. As one of the federal pilot projects to test integrated marine-use planning under the Oceans Act, the PNCIMA governance framework provides an opportunity for "learning by doing" that fits the geographic setting and socioeconomic conditions in the region (e.g., Hughes et al. 2007).

\section{Relationship of values to planning outcomes}

Values motivate people and lead to action; policymaking processes such as marine planning attempt to resolve conflicts among participants that arise as a result of incompatible values (Leung 1985). Policies or plans that are an expression of particular values may result in redistribution of power or resources. Values are often not explicitly stated, but they are fundamental to the acceptability of decisions and they often guide planning outcomes.

Applications of Haida values in fisheries were described by Jones and Williams-Davidson (2000). The Haida worldview, based on values such as respect, balance, and reciprocity, promotes a return to local or place-based management. In this way, the application of Haida values in marine-use planning has the potential to rebuild connections to place and strengthen local management authority. Haida involvement in marine-use planning will result in a community-based planning approach that is likely to be more conservation-focused than topdown initiatives because local communities typically attach direct values to coastal quality (Zagonari 2008). These values also require consideration of broader ecosystem effects resulting from specific marine-use activities such as the impacts of fishing practices on nontargeted species and habitats. As illustrated in Haida land-use planning, Haida values are likely to promote planning outcomes that reflect Haida interests in healthy marine ecosystems and sustainable economic development on Haida Gwaii. Haida values would also promote an ecosystem justice approach that considers the inherent value of all living and nonliving things, not just their value to humans (Coward et al. 2000). This worldview may be at odds with a centralized planning approach in which governments are focused on overall objectives related to national or provincial economic development. It may also result in a shift away from current approaches that emphasize the value of goods and services to humans, as well as the value of a single-species approach to fisheries management. 
If collaborative marine planning is to be effective, outcomes must ultimately reflect the values of First Nations participating in the PNCIMA initiative. The six Haida ethics and values described previously clearly demonstrate a commitment to responsible and respectful management of marine resources and ecosystems. O'Boyle and Jamieson (2006) have described DFO's approach to integrated management, which involves development of conceptual objectives across social, cultural, economic, and institutional dimensions, and thus resonates with the holistic Haida approach. As planning goals, objectives, strategies, and actions are defined through the PNCIMA process, Haida ethics and values provide a means to gauge the acceptability of proposed planning directions and outcomes.

\section{Developing an EBM framework}

EBM was a guiding principle in recent provincial land-use planning processes and is embodied in federal and provincial approaches to resource management and planning (Fisheries and Oceans Canada 2002, Coast Information Team 2004). Marine-use planning in the PNCIMA is also anticipated to adopt an ecosystem approach that respects the relationships between human activities, marine species, and habitats.

The Haida definition of EBM is consistent with the definition of the "ecosystem approach" in the Convention on Biological Diversity (2000):

\section{The Ecosystem Approach is a strategy for the integrated management of land, water and living resources that promotes conservation and sustainable use in an equitable way. The application of the Ecosystem Approach will help to reach a balance of the three objectives of the Convention: conservation; sustainable use; and the fair and equitable sharing of the benefits arising out of the utilization of genetic resources.}

Both EBM definitions, Haida and the Convention on Biological Diversity, incorporate biological, socioeconomic, and social equity components. The EBM approach in provincial land-use planning has similar elements (Coast Information Team 2004). Protected areas are a key element of land-use planning, and experience has demonstrated that First Nations have a special role in conservation and management of protected areas (Beltrán 2000, Stevens 1997).

For coastal First Nations, this role and associated responsibilities extends to the management of both terrestrial and marine ecosystems. For instance, the Council of the Haida already co-manages Gwaii Haanas National Park Reserve and Haida Heritage Site with Parks Canada and is working collaboratively with Parks Canada and DFO to establish an adjacent national marine conservation area reserve. In 2007, the Council of the Haida Nation also signed an agreement for planning and management of a new federal marine protected area, Sgaan Kinghlas or Bowie Hodgkins-Davidson Seamount chain. EBM is a key principle in both processes. Integrated oceans management in the PNCIMA provides an opportunity to apply First Nations-defined EBM in all marine planning and resource management, consistent with the experience of indigenous peoples in Canada's north (Berkes et al. 2005).

\section{Applications of traditional knowledge}

Information concerning traditional knowledge and use can be invaluable in improving our understanding of ecosystems (Johannes and Neis 2007). Traditional knowledge has increasingly proved its validity in fields such as management of fisheries and wildlife, and environmental assessment (Huntington 2000, Paci et al. 2002, Berkes et al. 2007, Houde 2007, Clark and Slocombe 2009). Canada's Oceans Strategy (Fisheries and Oceans Canada 2002), and federal legislation such as the Species at Risk Act (2003) and National Marine Conservation Areas Act (2002), identify traditional knowledge as key information to understand species and ecosystems.

Currently, the First Nations engaged in PNCIMA marine-use planning are documenting marine traditional knowledge and use and will investigate applying that information to planning at larger scales. As described earlier, products are expected to include maps that show species distribution and fishing locations, as well as a spatial database of map features and places. Protocols for sharing of information with Canada and among First Nations still need to be developed.

Understanding a complex system such as a global ecosystem or LOMA entails an understanding of the 
ecosystem interactions at all levels of the local-toglobal hierarchy (Berkes et al. 2006). Traditional knowledge will help to increase understanding of species and interactions, particularly at local scales and for species that are not fished commercially. The multigenerational aspect of First Nations knowledge can fill data gaps and help document trends and changes over time. For example, oral history related to Haida Gwaii herring indicated that herring stocks were significantly greater in the past before reduction fisheries escalated in Haida Gwaii in the 1950s (Jones 2007). Traditional knowledge can then be used to complement historic data and inform modeling of past ecosystems (e.g., use of modeling to develop fisheries policy options by Haggan et al. 1999).

\section{Linking marine planning at various scales}

Many issues in the PNCIMA region cross federal, provincial, and First Nation jurisdictional and departmental boundaries. DFO integrated management planning focuses on issues affecting conservation and sustainable use of marine resources in the PNCIMA as a whole. First Nations and the Province of British Columbia have an interest in planning at scales such as individual or aggregate First Nations territories. First Nations have already begun to assess issues within their traditional territories and this will ultimately contribute to broader planning strategies at the regional PNCIMA scale.

It is also critical that the PNCIMA initiative be consistent with other planning and management processes within PNCIMA to ensure that outcomes are effectively integrated. Although different planning processes can involve different agencies and levels of government, the tie that binds them together is often the participation of local First Nations. On Haida Gwaii, for example, the Council of the Haida Nation is engaged in PNCIMA-scale planning, local planning for Haida marine territory, planning for the proposed Gwaii Haanas National Marine Conservation Area Reserve, nearshore/ foreshore planning resulting from implementation of the land-use plan, and developing the Sgaan Kinghlas/Bowie Seamount marine protected area management plan. Haida involvement in all of these processes is an effective means to ensure consistency and coordination at different scales and across different federal and provincial agencies.

\section{CONCLUSIONS}

Court decisions and government policies relating to Aboriginal rights and title have affirmed the role of First Nations in resource planning and management. A government-to-government process, involving provincial and First Nations governments, was a key element to move land-use planning forward in advance of treaties in northern coastal BC. The current governance framework between First Nations and DFO for PNCIMA indicates that a similar model will be applied in marine planning. Experiences in terrestrial management and integrated oceans management to date have demonstrated the potential of new types of governance and community-based planning to facilitate policy dialogue and community action toward improved conservation and sustainable use.

BC First Nations' values and interests are playing a crucial role in PNCIMA planning processes and future policy development, thus shaping marine resource management in the region. A Haida marine-use vision, and associated ethics and values, demonstrate the Haida approach to integrated and ecosystem-based management. Haida values are promoting marine conservation and sustainable use in Haida Gwaii. In PNCIMA, their broader application has the potential to result in the following planning outcomes: a modern oceans governance process that involves First Nations; establishment of a network of marine protected areas, with placement and level of protection influenced by First Nations; a shift from centrallyplanned to more local place-based management of fisheries and other marine activities; and marine resource management that incorporates the principles of social equity and ecosystem justice as part of the application of First Nations' EBM. First Nations have been a catalyst for changes in resource management policy on land and are now partnering with DFO in integrated resource management and conservation in the oceans.

Responses to this article can be read online at: http://www.ecologyandsociety.org/voll5/iss 1/art12/ responses/ 


\section{Acknowledgments:}

Funding support for the Haida marine planning initiative is provided by DFO's Aboriginal Aquatic Resource and Oceans Management program, and the Gordon and Betty Moore Foundation.

\section{LITERATURE CITED}

Alley, J., and K. Topelko. 2007. Ocean governance arrangements in British Columbia. Presented at the "Oceans Governance on Canada's West Coast Workshop”, (Victoria, British Columbia, Canada, 2007) Maritime Awards Society of Canada. [online] URL: http://www.maritimeawards.ca/OGCWC/Docs/ Oceans Governance Arrangements.pdf.

Arkema, K. K., S. C. Abramson, and B. M. Dewsbury. 2006. Marine ecosystem-based management: from characterization to implementation. Frontiers in Ecology and the Environment 4:525-532.

Bastien-Daigle, S., J.-P. Vanderlinden, and $O$. Chouinard. 2008. Learning the ropes: lessons in integrated management of coastal resources in Canada's maritime provinces. Ocean and Coastal Management 51:96-125.

Beltrán, J., editor. 2000. Indigenous and traditional peoples and protected areas: principles, guidelines and case studies. IUCN, Gland, Switzerland and Cambridge, UK.

Berkes, F., M. K. Berkes, and H. Fast. 2007. Collaborative integrated management in Canada's North: the role of local and traditional knowledge and community-based monitoring. Coastal Management 35:143-162.

Berkes, F., R. Huebert, H. Fast, M. Manseau, and A. Diduck. 2005. Breaking ice: renewable resource and ocean management in the Canadian north. University of Calgary Press, Calgary, Canada.

Berkes, F., W. V. Reid, R. J. Wilbanks, and D. Capistano. 2006. Conclusions. Pages 315-331 in W. V. Reid, F. Berkes, T. Wilbanks, and D. Capistrano, editors. Bridging scales and knowledge systems: linking global science in assessments.
Millenium Ecosystem Assessment and Island Press, Washington, D.C., USA. Available online at: www .millenniumassessment.org/documents/bridging/ bridging.17.pdf.

Cicin-Sain, B., and R. W. Knecht. 1998. Integrated coastal and ocean management. Island Press, Washington, D.C., USA.

Clark, D. A., and D. S. Slocombe. 2009. Respect for grizzly bears: an aboriginal approach for coexistence and resilience. Ecology and Society 14(1): 42. [online] URL: http://www.ecologyandsociety.org/ articles/2892.html.

Coast Information Team. 2004. Ecosystem-based management framework. [online] URL: http://www .citbc.org/ebm.html.

Coastal First Nations-Turning Point Initiative (CFN-TPI). 2007. Sea of change: integrated marine use planning. [online] URL: http://www.coastalfirs tnations.ca/files/PDF/seaofchange.pdf.

Coastal First Nations-Turning Point Initiative (CFN-TPI). 2009. Into the deep blue: marine ecosystem-based management. CFN-TPI, Vancouver, BC, Canada. [online] URL: http://www.coastalfirst nations.ca/files/PDF/intothedeepblue.pdf.

Coates, K. 1999. The 'Gentle Occupation': the settlement of Canada and the dispossession of the First Nations. Pages 141-161 in P. Havemann, editor. Indigenous peoples rights in Australia, Canada and New Zealand. Oxford University Press, Aukland, New Zealand.

Convention on Biological Diversity (CBD). 2000. Decision V/6: ecosystem approach. Pages 103-109 in Decisions adopted by the Conference of the Parties to the Convention on Biological Diversity at its fifth meeting, Nairobi, 15-26 May 2000. Available online at: http://www.cbd.int/doc/decisions/ COP-05-dec-en.pdf.

Council of the Haida Nation. 2005. Haida land use vision-Haida Gwaii yah'guudang (respecting Haida Gwaii). [online] URL: http://ilmbwww.gov.bc. ca/slrp/lrmp/nanaimo/haidagwaii/docs/HLUVpublic. pdf.

Council of the Haida Nation. 2007. Towards a marine use plan for Haida Gwaii. [online] URL: http://www.haidanation.ca/Pages/Splash/Documents/ 
Towards a MUP.pdf.

Council of the Haida Nation and Province of British Columbia. 2007. Haida Gwaii strategic land use agreement. [online] URL: http://ilmbwww. gov.bc.ca/slrp/lrmp/nanaimo/haidagwaii/index.html

Coward, H., R. Ommer, and T. Pitcher. 2000. Just fish: ethics and Canadian marine fisheries. Institute of Social and Economic Research, Memorial University of Newfoundland, St. John's, Newfoundland, Canada.

Fast, H., D. B. Chiperzak, K. J. Cott, and G. M. Elliott. 2005. Integrated management planning in Canada's western Arctic. Pages 95-117 in F. Berkes, R. Huebert, H.Fast, M. Manseau, and A. Diduck, editors. Breaking ice: renewable resource and ocean management in the Canadian north. University of Calgary Press, Calgary, Alberta, Canada.

Fisheries and Oceans Canada (DFO). 2002. Canada's Oceans Strategy: our oceans, our futurepolicy and operational framework for integrated management of estuarine, coastal and marine environments of Canada. DFO, Ottawa, Ontario, Canada.

Fisheries and Oceans Canada (DFO). 2005. Canada's Oceans Action Plan: for present and future generations. DFO, Ottawa, Ontario, Canada.

Fisheries and Oceans Canada (DFO). 2007. Eastern Scotian Shelf Integrated Ocean Management Plan: strategic plan. ESSIM Planning Office, Oceans and Coastal Management Division, Dartmouth, Nova Scotia, Canada. Available online at: http://www.dfo-mpo.gc.ca/Library/333115.pdf

Fisheries and Oceans Canada (DFO) and British Columbia Ministry of Agriculture, Food and Fisheries. 2004. Memorandum of understanding respecting the implementation of Canada's Oceans Strategy on the Pacific coast of Canada. [online] URL: http://www.dfo-mpo.gc.ca/oceans-habitat/oceans/ ri-rs/bc-cb/index e.asp.

Fisheries and Oceans Canada (DFO) and First Nations of the Pacific North Coast. 2008. Memorandum of understanding on Pacific North
Coast Integrated Management Area collaborative oceans governance. [online] URL: http://www.pnc ima.org/governancedocuments.html.

Food and Agricultural Organization (FAO). 2003. Ecosystem approach to fisheries: issues, terminology, principles, institutional foundations, implementation and outlook. FAO Fisheries Technical Paper No. 443. FAO, Rome, Italy.

Haggan, N., A. Beattie, and D. Pauly, editors. 1999. Back to the future: reconstructing the Hecate Strait ecosystem. Fisheries Centre Research Report, Volume 7(3). UBC Fisheries Centre, Vancouver, British Columbia, Canada.

Harris, D. C. 2001. Fish, law and colonialism: the legal capture of salmon in British Columbia. University of Toronto Press, Toronto, Ontario, Canada.

Harris, D. C. 2002. Making native space: colonialism, resistance, and reserves in British Columbia. UBC Press, Vancouver, British Columbia, Canada.

Houde, N. 2007. The six faces of traditional ecological knowledge: challenges and opportunities for Canadian co-management arrangements. Ecology and Society 12(2): 34. [online] URL: http: //www.ecologyandsociety.org/vol12/iss2/art34/.

Hughes, T. P., L. H. Gunderson, C. Folke, A. H. Baird, D. Bellwood, F. Berkes, B. Crona, A. Helfgott, H. Leslie, J. Norberg, M. Nystrom, P. Olsson, H. Osterblom, M. Scheffer, H. Schuttenberg, R. Steneck, M. Tengo, M. Troell, B. Walker, J. Wilson, and B. Worm. 2007. Adaptive management of the Great Barrier Reef and the Grand Canyon World Heritage Areas. Ambio 37:586-592.

Huntington, H. P. 2000. Using traditional ecological knowledge in science: methods and applications. Ecological Applications 10(5):1270-1274.

Johannes, R., and B. Neis. 2007. The value of anecdote. Pages 41-58 in N. Haggan, B. Neis, and I. G. Baird, editors. Fisheries knowledge in fisheries science and management. Coastal Management Sourcebooks 4. UNESCO Publishing, Paris, France. 
Jones, R. 2006. Canada's seas and her First Nations: a colonial paradigm revisited. Pages 299-314 in D. R. Rothwell and D. L. VanderZwaag, editors. Towards principled oceans governance. Routledge, New York, New York, USA.

Jones, R. 2007. Application of Haida oral history to Pacific herring management. Pages 103-118 in N. Haggan, B. Neis, and I. G. Baird, editors. Fishers' knowledge in fisheries science and management. Coastal Management Sourcebooks 4. UNESCO Publishing, Paris, France.

Jones, R., and T. Williams-Davidson. 2000. Applying Haida ethics in today's fishery. Pages 100-115 in H. Coward, R. Ommer, and T. Pitcher, editors. Just fish: ethics and Canadian marine fisheries. Institute of Social and Economic Research, Memorial University of Newfoundland, St. John's, Newfoundland, Canada.

Jones, R., and S. Guénette. 2002. First nation issues and MPA planning. Pages 1427-1437 in S. Bondrup-Nielsen, N. Munro, G. Nelson, J. Willison, T. Herman, and P. Eagles, editors. Managing protected areas in a changing world, Proceedings of the Fourth International Conference on Science and Management of Protected Areas. Science and Management of Protected Areas Association, Nova Scotia, Canada.

Leung, H. L. 1985. Towards a subjective approach to policy planning and evaluation: common-sense structured. Ronald P. Frye and Company, Winnipeg, Manitoba, Canada.

Lucas, B. G., S. Verrin, and R. Brown, editors. 2007. Ecosystem overview: Pacific North Coast Integrated Management Area (PNCIMA). Canadian Technical Report of Fisheries and Aquatic Sciences 2667. Institute of Ocean Sciences, DFO, Sidney, British Columbia, Canada.

McLeod, K. L., J. Lubchenco, S. R. Palumbi, and A. A. Rosenberg. 2005. Scientific consensus statement on marine ecosystem-basedmanagement. Communication Partnership for Science and the Sea. Available online at: http://compassonline.org/ pdf files/EBM Consensus Statement v12.pdf.

O'Boyle, R., and G. Jamieson. 2006. Observations on the implementation of ecosystem-based management: experiences on Canada's east and west coasts. Fisheries Research 9:1-12.
Olson, S., J. Tobey, and M. Kerr. 1997. A common framework for learning from ICM experience. Ocean and Coastal Management 37:155-174.

Olson, S. B. 2003. Frameworks and indicators for assessing progress in integrated coastal management initiatives. Ocean and Coastal Management 46:347-361.

Paci, C., A. Tobin, and P. Robb. 2002. Reconsidering the Canadian Environmental Impact Assessment Act: a place for traditional environmental knowledge. Environmental Impact Assessment Review 22:111-127.

PNCIMA Secretariat. 2009. Pacific North Coast Integrated Management Area (PNCIMA): summary of issues, challenges \& opportunities. [online] URL: http://www.pncima.org/2009 Forum/backgroundd ocuments.html.

Pope, J. G., and D. Symes. 2002. An ecosystem based approach to the common fisheries policy: defining the goals. Joint Nature Conservation Committee (JNCC), London, UK.

Province of British Columbia. 2005. The new relationship. [online] URL: www.gov.bc.ca/themes/ new relationship.html.

Province of British Columbia. 2006. Province announces a new vision for coastal $B C$. Backgrounder 2006AL0002-000066, February 7, 2006. [online] URL: http://www2.news.gov.bc.ca/n ews releases 2005-2009/2006AL0002-000066.htm

Rutherford, R. J., G. J. Herbert, and S. S. CoffenSmout. 2005. Integrated ocean management and the collaborative planning process: the Eastern Scotian Shelf Integrated Management (ESSIM) initiative. Marine Policy 29:75-83.

Stevens, S. 1997. Conservation through cultural survival: indigenous peoples and protected areas. Island Press, Washington, D.C., USA.

Zagonari, F. 2008. Integrated coastal management: top-down vs. community-based approaches. Journal of Environmental Management 88:796-804. 